\title{
Clinical use of gadobutrol for contrast-enhanced magnetic resonance imaging of neurological diseases
}

This article was published in the following Dove Press journal:

Reports in Medical Imaging

28 February 2012

Number of times this article has been viewed

\section{Kenneth T Cheng' \\ Hannah Y Cheng ${ }^{2}$ \\ Kam Leung ${ }^{3}$}

'Department of Radiology and Imaging Sciences, Clinical Center, National Institutes of Health, Bethesda, MD, USA; ${ }^{2}$ Freelance Technical Writer, New Orleans, LA, USA; ${ }^{3}$ National Center for Biotechnology Information, National Library of Medicine, National Institutes of Health, Bethesda, MD, USA
Correspondence: Kam Leung Molecular Imaging and Contrast Agents Database, National Center for Biotechnology Information, National Institutes of Health, 8600 Rockville Pike, Bethesda, MD 20894, USA

$\mathrm{Tel}+$ I 30I 4026747

Fax +I 30I 4804637

Email leung@mail.nih.gov
Abstract: Contrast-enhanced magnetic resonance imaging (CE-MRI) is an important clinical tool for diagnosing neurological diseases. The appropriate use of a suitable MRI contrast agent or contrast pharmaceutical is essential for CE-MRI to produce desirable diagnostic images. Currently, there are seven contrast agents (CAs) or pharmaceuticals approved for clinical imaging of the central nervous system (CNS) in the US, Europe, or Japan. All of the clinically approved CAs are water-soluble gadolinium-based contrast agents (GBCAs) which do not penetrate the CNS blood-brain barrier (BBB). These agents are used for imaging CNS areas without a BBB, or various pathologies, such as tumors and infection that break down the BBB and allow CAs to enter into the surrounding parenchyma. Clinically, GBCAs are most useful for detecting primary and secondary cerebral neoplastic lesions. Among these CNS GBCAs, gadobutrol (Gd-BTDO3A, Gadovist ${ }^{\mathrm{TM}}$ ) is a neutral, nonionic, macrocyclic compound that showed promising results from clinical trials of CNS imaging. In comparison with other GBCAs, Gd-BT-DO3A has relatively high in vitro kinetic stability and $r_{1}$ relaxivity. Gd-BT-DO3A has been recently approved by the US Food and Drug Administration (FDA) in 2011 for CNS imaging. A review of available literature shows that Gd-BT-DO3A exhibits similar safety and clinical efficacy profiles to other GBCAs. Gd-BT-DO3A has the distinguishing feature that it is the only clinical agent commercially available in a formulation of $1.0 \mathrm{M}$ concentration with a relatively higher in vitro $\mathrm{T}_{1}$ shortening per unit volume than other clinical GBCAs which are only available in $0.5 \mathrm{M}$ concentration. This double concentration of Gd-BT-DO3A may allow a relatively higher concentration of the agent to localize in the CNS and produce a better contrast enhancement at the same clinical dose as other GBCAs. Several recent published multicenter clinical trials appeared to support this potential advantage of Gd-BT-DO3A.

Keywords: Gadovist, Gd-BT-DO3A, CE-MRI, CNS imaging, MRI contrast agent, gadolinium

\section{Introduction}

Current clinical magnetic resonance imaging (MRI) produces images by measuring the radiofrequency $(\mathrm{RF})$ signals that arise from exposing water protons $\left({ }^{1} \mathrm{H}\right)$ in living tissues of the patient to a high external magnetic field created by the clinical MRI imagers. ${ }^{1,2}$ Because the magnetic properties of ${ }^{1} \mathrm{H}$ are sensitive to the local microstructure and tissue composition, detailed anatomical images of high resolution as well as physiological information such as tissue perfusion and blood flow can be quantified by specific MRI measurement. The normal contrast in the clinical MRI images represents the relative difference in signal intensities between two adjacent regions displayed on a gray (or color) scale. The major contributing factors to the signal intensities are the proton longitudinal relaxation time $\left(\mathrm{T}_{1}\right)$ and transverse relaxation time $\left(\mathrm{T}_{2}\right)$. However, there are many pathological conditions 
that do not lead to sufficient MRI signal intensity difference between normal and abnormal tissues because of the intrinsic insensitivity of MRI. In these conditions, the pathology may be detected by introducing exogenous MRI contrast agents (CAs) or contrast pharmaceuticals to locally change the magnetic properties of the diseased tissue. Frequently, the sensitivity and accuracy of clinical MRI in diagnosis of diseases are significantly increased by the utilization of CAs that have been proven to be safe for human use.

MRI plays an important role in the detection, diagnosis, and management of patients with various neurological diseases. ${ }^{3-5}$ With recent advances in technologies, MRI offers high physiological sensitivity and spatial resolution of the brain. ${ }^{6,7}$ Some of these capabilities arise from the use of exogenous contrast pharmaceuticals to enhance the contrast between normal and abnormal tissues of the central nervous system (CNS). This contrast-enhanced MRI (CE-MRI) approach improves sensitivity, increasing the detection and delineation of normal and pathological structures in CNS clinical studies. Current clinical CE-MRI of the CNS mainly utilizes CAs that consist of the paramagnetic gadolinium(III) $\left(\mathrm{Gd}^{3+}\right)$ chelated to various non-toxic molecules to reduce the inherent free $\mathrm{Gd}^{3+}$ ion biological toxicity. ${ }^{6,8-10} \mathrm{Gd}^{3+}$, a lanthanide metal ion with seven unpaired electrons, has been shown to be very effective at enhancing proton relaxation because of its high magnetic moment and very labile water coordination. ${ }^{2,6-9}$ These water-soluble paramagnetic contrast agents are generally metal chelates that work as positive CAs by shortening the $\mathrm{T}_{1}, \mathrm{~T}_{2}$, and $\mathrm{T}_{2} *$ relaxation time constants of surrounding water protons to indirectly produce the signal-enhancing effect. ${ }^{8} \mathrm{At}$ normal clinical doses of $0.1-0.2 \mathrm{mmol} / \mathrm{kg}$, the $\mathrm{T}_{1}$ effect tends to dominate. All of the gadolinium-based CAs (GBCAs) that are approved for clinical use in humans are nonspecific agents, and their clinical use in CNS imaging is limited by the blood-brain barrier (BBB). There are negative CAs such as superparamagnetic particles/nanoparticles which primarily shorten $\mathrm{T}_{2}$ and $\mathrm{T}_{2} *$ but none of these agents are commercially available for clinical applications for CNS imaging. With a better understanding of the complex contrast enhancement mechanism as well as advances in the field of cellular and molecular imaging, specific tissue/molecular-targeted CAs that can penetrate the $\mathrm{BBB}$ and smart-activated/responsive CAs are under active investigations that may lead to more specific targeted imaging in the future. , $2,11-14^{-14}$

The GBCAs for CE-MRI of CNS are primarily focused on detecting CNS lesions. ${ }^{4,5}$ After intravenous (IV) injection, these low molecular weight gadolinium chelates distribute from the bloodstream into the intravascular, extravascular, and extracellular spaces of the body. ${ }^{3}$ These agents rapidly equilibrate between intravascular and extravascular spaces with up to $50 \%$ first pass extraction fractions. The CNS presents a different environment from the rest of the body because of the existence of the BBB. ${ }^{15,16}$ The BBB is a network of blood vessels formed by very closely spaced endothelial cells with tight junctions to prevent diffusion of large molecular weight substances into the brain parenchyma. As a result, the use of CAs in the CNS is a challenge but also provides considerably different diagnostic applications, analysis opportunities and physiological inferences. ${ }^{3,16}$ All current commercially available MRI contrast pharmaceuticals do not cross the intact BBB. An intact BBB prevents the extravasation of these agents from blood vessels into the surrounding brain parenchyma. They are retained intravascularly in the CNS regions with intact BBB. Thus, contrast enhancement with these agents only occurs in the CNS regions without the BBB in healthy adult brains. These regions include the choroid plexus, the pituitary gland and infundibulum, the cavernous sinus, and nasal mucosa. Other possible structures may include vessels, dura mater, and falx cerebri. However, a variety of pathological conditions such as tumors, infarctions, infection, and acute demyelination may cause the BBB to break down and allow these MRI contrast agents to cross into the extracellular space of CNS lesions.

Table 1 shows some examples of the CE-MRI of selected CNS pathologies. ${ }^{15}$ In these cases of BBB breakdown, small or multiple CNS lesions are more clearly delineated with contrast enhancement. More importantly, contrast enhancement can highlight lesion vasculature, delineate the extent of disease, and confirm the impression of normal or nonmalignant tissues. ${ }^{1,2,5}$ Thus, CE-MRI of the brain lesions can provide important anatomical information about brain pathology, detailed depiction of

Table I Examples of CE-MRI used for selected CNS lesions ${ }^{5}$

\begin{tabular}{|c|c|}
\hline CNS lesions & $\begin{array}{l}\text { Enhancement/clinical } \\
\text { observations }\end{array}$ \\
\hline Intraparenchymal & Early detection of small metastases \\
\hline tumors/metastases & $\begin{array}{l}\text { Useful for delineation and } \\
\text { specificity of high grade gliomas }\end{array}$ \\
\hline Meningeal tumors/meningioma & Focal/nodular enhancement \\
\hline $\begin{array}{l}\text { Cerebellopontine angle and } \\
\text { internal/auditory canal lesions }\end{array}$ & Very strong enhancement \\
\hline $\begin{array}{l}\text { Inflammation/acute disseminated } \\
\text { encephalomyelitis }\end{array}$ & In case of $\mathrm{BBB}$ breakdown \\
\hline Infection & $\begin{array}{l}\text { In case of BBB breakdown, there } \\
\text { is rim enhancement in abscesses }\end{array}$ \\
\hline Ischemia and acute infarction & Depending on stage \\
\hline
\end{tabular}

Abbreviations: CE-MRI, contrast-enhanced magnetic resonance imaging; CNS, central nervous system; BBB, blood-brain barrier. 
lesion morphology, and the overall extent of disease. Combined with advanced functional MRI techniques such as dynamic contrast-enhanced perfusion-weighted imaging, CE-MRI also provides physiological information regarding the hemodynamics and neoangiogenic status of the CNS lesion. ${ }^{11}$

Clinically, CE-MRI is most commonly used to evaluate primary and secondary CNS tumors. ${ }^{3} \mathrm{CE}-\mathrm{MRI}$ of CNS tumors provides sensitive detection and an accurate description of the disease in terms of tumor grade and aggressiveness. CE-MRI is an invaluable tool for identifying critical structures for neurosurgical or radiotherapeutic intervention. In addition, it is also very useful for determining and monitoring treatment response.

\section{Gadolinium-based MRI contrast pharmaceuticals used in clinical CE-MRI}

There are various GBCAs that are either available for clinical use in humans or under development at various stages of investigation. ${ }^{1,6,11,17}$ They can be classified based on their molecular structures or physicochemical properties. For clinical applications, these GBCAs are most commonly classified based on their in vivo tissue distribution: extracellular, intracellular, tissue-specific, or blood pool/intravascular contrast agents (Table 2). ${ }^{1,3,6,11,17,18}$ There are nine GBCAs approved

Table 2 Approved clinical intravenous GBCAs in the US, EU, and Japan

\begin{tabular}{|c|c|c|c|}
\hline $\begin{array}{l}\text { GBCA } \\
\text { (trade name) }\end{array}$ & $\begin{array}{l}\text { Approved } \\
\text { indications }\end{array}$ & $\begin{array}{l}\text { Approval } \\
\text { status }\end{array}$ & $\begin{array}{l}\text { Approved adult } \\
\text { CNS dose } \\
(\mathrm{mmol} / \mathrm{kg})\end{array}$ \\
\hline $\begin{array}{l}\text { Gadopentate } \\
\text { (Magnevist }^{\mathrm{TM}} \text { ) }\end{array}$ & $\begin{array}{l}\text { CNS, } \\
\text { whole body }\end{array}$ & $\begin{array}{l}\text { US, EU, } \\
\text { Japan }\end{array}$ & $0.1-0.2$ \\
\hline $\begin{array}{l}\text { Gadodiamide } \\
\left(\text { Omniscan }^{\mathrm{TM}}\right)\end{array}$ & $\begin{array}{l}\text { CNS, } \\
\text { whole body }\end{array}$ & $\begin{array}{l}\text { US, EU, } \\
\text { Japan }\end{array}$ & $0.1-0.3$ \\
\hline $\begin{array}{l}\text { Gadoterate } \\
\left.\text { (Dotarem }{ }^{\mathrm{TM}}\right)\end{array}$ & $\begin{array}{l}\text { CNS, } \\
\text { whole body }\end{array}$ & EU & $0.1-0.3$ \\
\hline $\begin{array}{l}\text { Gadoteridol } \\
\text { (Prohance }^{\mathrm{TM}} \text { ) }\end{array}$ & $\begin{array}{l}\text { CNS, } \\
\text { whole body }\end{array}$ & $\begin{array}{l}\text { US, EU, } \\
\text { Japan }\end{array}$ & $0 \mathrm{I}-0.3$ \\
\hline $\begin{array}{l}\text { Gadobutrol } \\
\text { (Gadovist }^{\mathrm{TM}} \text { ) }\end{array}$ & CNS & US, EU & $0.1-0.3$ \\
\hline $\begin{array}{l}\text { Gadobenate } \\
\text { (MultiHance }{ }^{\mathrm{TM}} \text { ) }\end{array}$ & CNS, liver & US, EU & 0.1 \\
\hline $\begin{array}{l}\text { Gadoversetamide } \\
\left.\text { (OptiMARK }{ }^{\mathrm{TM}}\right)\end{array}$ & CNS, liver & US & 0.1 \\
\hline $\begin{array}{l}\text { Gadoxetic acid } \\
\left(\text { Primovist }^{\mathrm{TM}}\right) \text { - EU } \\
\left(\text { Eovist }^{\mathrm{TM}}\right)-\text { USA }\end{array}$ & Liver & US, EU & Not approved \\
\hline $\begin{array}{l}\text { Gadofosveset } \\
\text { (Vasovist }^{\mathrm{TM}} \text { ) }\end{array}$ & $\begin{array}{l}\text { Abdominal and } \\
\text { limb vessels }\end{array}$ & EU & Not approved \\
\hline
\end{tabular}

Abbreviations: GBCA, gadolinium-based contrast agents; CNS, central nervous system. for intravenous administration for CE-MRI. Seven of these agents are approved for used in CE-MRI of the CNS. All of these agents are non-specific extracellular agents and lack specificity for typing cancers for the purpose of differential diagnosis. ${ }^{13,14}$

Gadopentetate dimeglumine (Gd-DTPA) was the first intravenous MRI contrast agent used clinically, and a number of similar Gd chelates have been developed in an effort to further improve clinical efficacy, patient safety, and patient tolerance. ${ }^{1,6}$ The major chemical differences among these GBCAs are the presence or absence of overall charge, ionic or nonionic, and their ligand frameworks (linear or macrocyclic) (Table 3). ${ }^{3,18,19}$

Some important properties of GBCAs are high solubility, high relaxivity, low toxicity, low osmolality, thermodynamic and kinetic stability, and number of water coordination sites. . $7,18,20,21$ Chemically, hydrophilicity is important because high overall hydrophilicity is associated with very low protein binding and good biological tolerance. All GBCAs are nine-coordinate complexes in which a ligand occupies eight binding sites at the $\mathrm{Gd}^{3+}$ metal center, and the ninth coordination site is occupied by a water molecule. Kinetic stability is an important factor as related to the safety of GBCAs in causing nephrogenic systemic fibrosis (NSF). 18,19,22,23 The kinetic stability is generally related to the potential dechelation reaction or transmetallation of the GBCAs that results in the release of the toxic free $\mathrm{Gd}^{3+}$ in vivo. Idee et $\mathrm{al}^{18}$ proposed three classes of GBCAs based on their experimentally determined in vitro results in the presence of $\mathrm{Zn}^{2+}$ at $\mathrm{pH} 7.4$ (Table 2). ${ }^{19,22,23}$ The classes are as follows:

1. macrocyclic chelates (Gd-DOTA, Gd-HP-DO3A, and Gd-BT-DO3A) with very high kinetic stability;

2. ionic, open-chain chelates (Gd-DTPA, Gd-BOPTA) with moderate kinetic stability;

3. nonionic, open-chain chelates (Gd-DTPA-BMA and Gd-DTPA-BMEA) with poor kinetic stability.

Both renal and extrarenal toxicities have been reported following the clinical use of GBCAs in patients with underlying kidney disease. ${ }^{24-26}$ In 2007, the United States Food and Drug Administration requested that all manufacturers of GBCAs add new warnings about how exposure to GBCAs increases the risk for NSF in patients with advanced kidney disease. The stability of GBCAs appears to be an important factor in the pathogenesis of $\mathrm{NSF}^{7}$ It is postulated that GBCAs of relatively low stability may release free $\mathrm{Gd}^{3+}$ ions that lead to the initiation of the fibrosis process. Idee et $\mathrm{al}^{18}$ suggested that high kinetic stability combined with a 


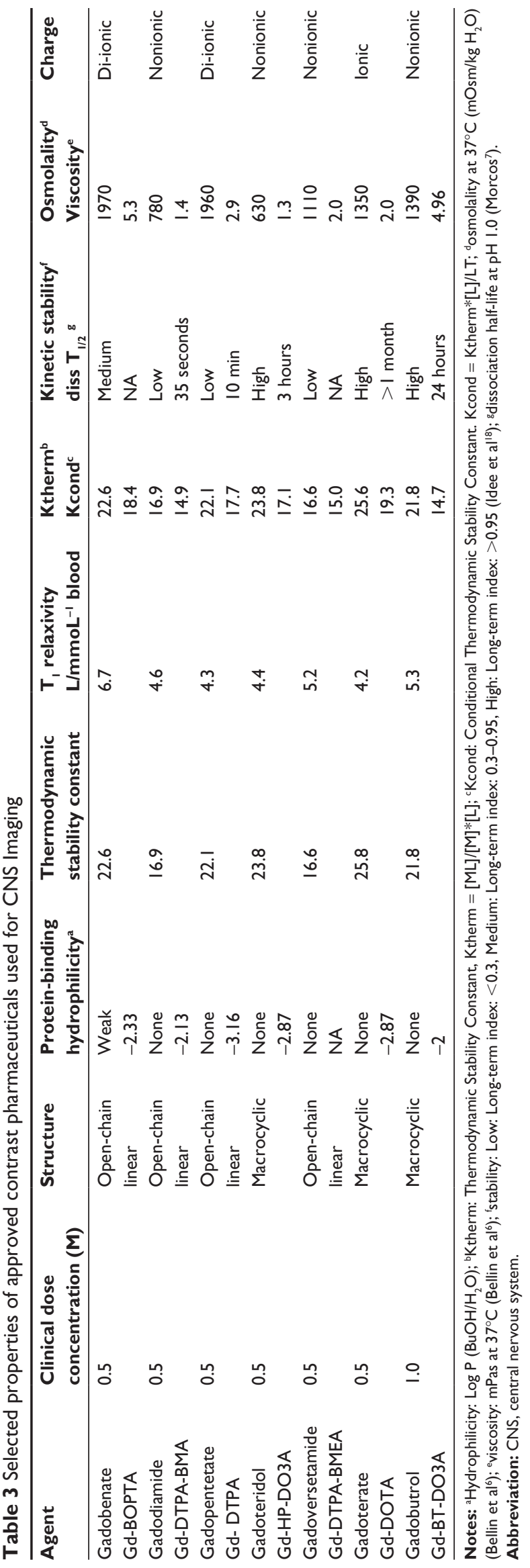

high thermodynamic stability can minimize the amount of free $\mathrm{Gd}^{3+}$ in vivo.

\section{Development of gadobutrol}

Based on the aforementioned physicochemical properties required for a clinically useful GBCA, Gd-BT-DO3A was developed for lower toxicity and higher dose concentration. Gd-BT-DO3A has a macrocyclic framework and is neutral. ${ }^{21,27}$ The BT-DO3A ligand was developed based on the belief that high overall hydrophilicity of an agent is generally associated with very low protein binding and good biological tolerance. ${ }^{21}$ It is a modification of the Gd-DO3A compound in which a trihydroxybutyl group is attached to the macrocyclic ligand to ensure high hydrophilicity. The ligand contains two chiral carbons at $\mathrm{C}-13$ and $\mathrm{C}-14$, and therefore the product is a racemic mixture of $(13 R, 14 S)$ - and $(13 S, 14 R)$-. The Gd(III) in Gd-BT-DO3A has a coordination number of 9. Gd-BT-DO3A is a water-soluble, highly hydrophilic compound with a partition coefficient between n-butanol and buffer at $\mathrm{pH} 7.6$ of $\sim 0.006 .{ }^{28}$

Gd-BT-DO3A was first synthesized by Vogler et $\mathrm{al}^{29}$ based on the general method for preparing the macrocyclic core using the Richman-Atkins method. Later, Platzek et $\mathrm{al}^{21}$ described three approaches to synthesizing the BT-DO3A ligand. One approach was preferred because it involved fewer steps and allowed scaled-up production for clinical applications. In this approach, 1-(1-[hydroxymethyl]-2,3dihydroxypropyl)-1,4,7,10-tetraazacyclododecane tetrahydrochloride was first prepared. The compound was then reacted with chloroacetic acid at $70^{\circ} \mathrm{C}$ and $\mathrm{pH} 9-10$ for 18 hours. Gd-BT-DO3A was then prepared by adding $\mathrm{Gd}_{2} \mathrm{O}_{3}$ to the ligand in water and stirring at $90^{\circ} \mathrm{C}$ for 6 hours. Cation and anion exchange resins were then added at room temperature, and the mixture was stirred for 30 minutes. The resins were recollected by filtration, and charcoal was added to the filtrate and refluxed for 1 hour. The solution was filtered and evaporated to dryness. The residue was re-dissolved in water and ethanol, and then was refluxed for 2 hours. Gd-BTDO3A was collected by filtration and drying under vacuum (12 hours at $60^{\circ} \mathrm{C}$ ). The final yield was $87 \%$.

\section{In vitro and preclinical animal studies of Gd-BT-DO3A}

Pintaske et al ${ }^{30}$ determined the in vitro relaxivity of Gd-BTDO3A and other compounds (Gd-DTPA and Gd-BOPTA) in human plasma obtained from healthy volunteers. Measurements of Gd-BT-DO3A in concentrations of $0.01 \mathrm{mM}$ up to $64 \mathrm{mM}$ at $37^{\circ} \mathrm{C}$ were made with $0.2-, 1.5-$, and 
3.0-Tesla $(\mathrm{T})$ clinical scanners. The longitudinal relaxation rates $\left(\mathrm{r}_{1}\right.$; liter $\left.\times \mathrm{mmoL}^{-1} \times \mathrm{s}^{-1}\right)$ of Gd-BT-DO3A were 5.5 \pm 0.3 , $4.7 \pm 0.2$, and $3.6 \pm 0.2$, at $0.2,1.5$, and $3 \mathrm{~T}$, respectively. The transverse relaxation rates $\left(\mathrm{r}_{2}\right.$; liter $\left.\times \mathrm{mmoL}^{-1} \times \mathrm{s}^{-1}\right)$ were $10.1 \pm 0.3,6.8 \pm 0.2$, and $6.3 \pm 0.3$, at $0.2,1.5$, and $3 \mathrm{~T}$, respectively. In comparison, these values were lower for Gd-DTPA but higher for Gd-BOPTA.

Vogler et $\mathrm{al}^{29}$ measured the in vitro physicochemical properties of Gd-BT-DO3A. The osmolality was found to be 0.57 $\mathrm{osmol} / \mathrm{kg}$ for the $0.5 \mathrm{M}$ concentration and $1.39 \mathrm{osmol} / \mathrm{kg}$ for the $1 \mathrm{M}$ concentration. The distribution coefficient (butanol/ water) was 0.006 , and the viscosity was $1.43 \mathrm{cP}$ for the $0.5 \mathrm{M}$ concentration and $3.7 \mathrm{cP}$ for the $1 \mathrm{M}$ concentration. The $\mathrm{T}_{1}$-relaxivity (liter $\times \mathrm{mmoL}^{-1} \times \mathrm{s}^{-1}$ ) in plasma was determined to be 5.6 at $0.45 \mathrm{~T}$ and 6.1 at $2 \mathrm{~T}$. There was negligible protein binding of about $2.7 \%$ in plasma. With use of rat mast cells, the $\mathrm{I}_{50}$ (the concentration at which histamine was released) was found to be greater than $250 \mathrm{mM}$. The $I_{50}$ value for lysozyme inhibition (the concentration at which $50 \%$ of the enzyme was inhibited) was greater than $300 \mathrm{mM}$.

Vogler et $\mathrm{al}^{29}$ studied the long-term elimination and biodistribution of $0.25 \mathrm{mmol} / \mathrm{kg}$ Gd-BT-DO3A in rats. More than $90 \%$ of the intraperitoneally injected dose (ID) was excreted by the kidneys in 2 hours and $100 \%$ in 7 days. The total amount remaining in the body decreased from $0.71 \%$ ID on day 1 to $0.15 \%$ ID on day 7 after injection. The acute toxicity (lethal dose $\left[\mathrm{LD}_{50}\right]$ ) in mice was $23 \mathrm{mmol} / \mathrm{kg}$. In a neural tolerance study, the median $\mathrm{LD}_{50}$ (lethal dose; $n=10$ ) and effective dose $\left(\mathrm{ED}_{50}\right)$ of Gd-BT-DO3A in rats after intracisternal injection were $86 \mu \mathrm{mol} / \mathrm{kg}$ and $18 \mu \mathrm{mol} / \mathrm{kg}$, respectively. In comparison, the $\mathrm{LD}_{50}$ and $\mathrm{ED}_{50}$ for Gd-DTPA were $740 \mu \mathrm{mol} / \mathrm{kg}$ and $73 \mu \mathrm{mol} / \mathrm{kg}$, respectively. The study suggested that macrocyclic compounds had lower cerebral tolerance and that linear compounds had higher cerebral tolerance. Imaging studies in rat models with cerebral infarct, brain tumors, and intramuscular tumors showed contrast enhancements in all three pathologic areas. A dose-dependent increase in the signal intensity of the intramuscular tumors was observed. Several rat studies ${ }^{31-35}$ showed that Gd-BTDO3A was effective in providing contrast enhancement for MRI in glioma, brain ischemia, hepatocellular carcinoma, and the lymphatic system.

Attenberger et $\mathrm{al}^{36}$ compared lesion enhancement using $1 \mathrm{M}$ Gd-BT-DO3A concentration with $0.5 \mathrm{M}$ concentration Gd-DTPA and Gd-DOTA in a rat brain glioma model at $3 \mathrm{~T}$ MRI. At doses of $0.1 \mathrm{mmol} / \mathrm{kg}$ of all three agents, the results of groups of 9-10 rats showed Gd-BT-DO3A produced significantly higher signal-to-noise ratio (SNR) and contrast-to-noise ratio (CNR) than those of Gd-DTPA and Gd-DOTA. The authors concluded that the superior $\mathrm{T}_{1}$ relaxivity property of Gd-BT-DO3A translated into more effective brain tumor enhancement at 3 T MRI imaging than both Gd-DTPA and Gd-DOTA. In a similar study at $1.5 \mathrm{~T}$ MRI, the same group of investigators ${ }^{37}$ also found consistently greater tumor enhancement produced by Gd-BE-DO3A than those of Gd-DTPA and Gd-DOTA. Kramer et al ${ }^{38}$ also found Gd-BT-DO3A (0.1 mmol/kg) produced significantly higher CNR and SNR than Gd-DOTA $(0.15 \mathrm{mmol} / \mathrm{kg})$ in a rat brain glioma model at 1.5 and $3 \mathrm{~T}$ MRI.

Vogler et $\mathrm{al}^{29}$ performed Gd-BT-DO3A pharmacokinetics studies in beagle dogs. The elimination $t_{1 / 2}$ and the plasma clearance were $45 \pm 3.6$ minutes and $3.75 \pm 0.30 \mathrm{~mL} / \mathrm{minute} / \mathrm{kg}$, respectively. The total volume of distribution at steady state $\left(\mathrm{V}_{\mathrm{ss}}\right)$ was $0.23 \pm 0.02 \mathrm{~L} / \mathrm{kg}$. High-performance liquid chromatography analysis of the plasma and urine samples showed that Gd-BT-DO3A was not metabolized.

\section{Clinical studies of Gd-BT-DO3A}

Staks et $\mathrm{al}^{39}$ investigated the pharmacokinetics, dose proportionality, and tolerability of Gd-BT-DO3A in healthy volunteers. Two double-blind, randomized, placebo-controlled Phase I studies were conducted for testing a low concentration $(0.5 \mathrm{M}$; doses $=0.04,0.1,0.2,0.3$, and $0.4 \mathrm{mmol} / \mathrm{kg}$; $n=55)$ and a high concentration $(1 \mathrm{M}$; doses $=0.3,0.4$, and $0.5 \mathrm{mmol} / \mathrm{kg} ; n=36$ ). From the data for 24 volunteers, pharmacokinetic parameters were calculated from an open two-compartment model. The values for plasma elimination half-life $\left(t_{1 / 2 \mathrm{p}, \beta} ; \mathrm{h}\right), \mathrm{V}_{\mathrm{ss}}$ (liter/kg), renal clearance $(\mathrm{mL} / \mathrm{min} /$ $\mathrm{kg}$ ), and 72-hour total renal excretion (Urine, 72 hours [\% ID]) for a $0.1 \mathrm{mmol} / \mathrm{kg}$ dose were $1.78 \pm 0.43,0.21 \pm 0.02$, $1.56 \pm 0.18$, and $98 \pm 3.33$, respectively. For a $0.4 \mathrm{mmol} / \mathrm{kg}$ dose, these values were $1.33 \pm 0.21,0.15 \pm 0.02,1.45 \pm 0.22$, and $96.6 \pm 5.61$, respectively. Plasma Gd-BT-DO3Al decreased bioexponentially, and the volume of distribution was within the extracellular fluid space. Elimination occurred primarily through the renal route. Biotransformation analysis of the urine and plasma samples revealed no metabolites from Gd-BT-DO3A. No significant changes were observed in serum chemistry/hematology or urine chemistry/ urinalysis. No clear dose-dependent adverse events were found between the low-dose and high-dose studies. The most common adverse events were smell sensation (12.5\%) and taste sensation (15\%). Essig et al ${ }^{40}$ compared $1 \mathrm{M}$ Gd-BTDO3A with 0.5 M Gd-BOPTA in a Phase I, single-blinded, randomized intra-individual $1.5 \mathrm{~T}$ MRI brain perfusion imaging study. Doses of 0.1 and $0.2 \mathrm{mmol} / \mathrm{kg}$ were studied 
in 12 male healthy volunteers. It was reported that both agents achieved similarly high-quality, diagnostically valid perfusion maps.

Tombach and Heindel ${ }^{41}$ and Huppertz and Rohrev ${ }^{42}$ summarized studies for the clinical applications of $1 \mathrm{M}$ Gd-BTDO3A. In 29 Phase I to Phase III studies (2523 subjects and 2662 doses), Gd-BT-DO3A was distributed in the extracellular fluid with a plasma terminal $t_{1 / 2}$ of $1.7-2$ hours. Approximately $98 \%$ of the dose was excreted unchanged in the urine within 12 hours. The studies indicated that $1 \mathrm{M}$ Gd-BT-DO3A had an excellent safety profile with doses ranging from 0.04 to $1.5 \mathrm{mmol} / \mathrm{kg}$. Overall, $8.5 \%$ of the patients reported related and unrelated adverse events. For contrast enhancement, analysis of efficacy data showed results comparable to results of other commercially available $0.5 \mathrm{M}$ Gd-chelates in studies of the CNS (677 patients) and angiography (676 patients). In a study of the pharmacokinetics of $1 \mathrm{M}$ Gd-BT-DO3A in 21 patients with chronic renal failure, Tombach et $\mathrm{al}^{43}$ reported that the extracellular distribution of Gd-BT-DO3A remained unchanged but the mean elimination $\mathrm{t}_{1 / 2}$ increased compared with that of healthy volunteers. Hahn et $\mathrm{al}^{44}$ studied the pharmacokinetics and safety of Gd-BT-DO3A in 130 pediatric patients aged 2-17 years. The authors concluded that no adjustment for the adult dose of $0.1 \mathrm{mmol} / \mathrm{kg}$ is necessary for this age range and that Gd-BT-DO3A was safe and well tolerated in the study.

Anzalone et $\mathrm{al}^{45}$ and $\mathrm{Kim}$ et $\mathrm{al}^{46}$ compared $1 \mathrm{M}$ Gd-BT-DO3A with $0.5 \mathrm{M} \mathrm{Gd-DTPA} \mathrm{in} \mathrm{their} \mathrm{clinical} \mathrm{perfor-}$ mance of detecting brain metastases at $1.5 \mathrm{~T}$ MRI. At equal Gd dosage $(0.1 \mathrm{mmol} / \mathrm{kg})$, Anzalone et $\mathrm{al}^{45}$ reported that Gd-BT-DO3A appeared to produce improved lesion conspicuity in ten out of the same group of 27 patients with at least one cerebral metastasis. Using double doses $(0.2 \mathrm{mmol} / \mathrm{kg})$ of both Gd-BT-DO3A and Gd-DTPA, Kim et $\mathrm{al}^{46}$ found Gd-BT-DO3A detected 25 additional lesions than that of Gd-DTPA (130 lesions) in the same 27 patients. The mean CNR was significantly higher $(P=0.00011)$ with Gd-BTDO3A $(2.17 \pm 0.19)$ than that of Gd-DTPA(1.9 \pm 0.26$)$.

In a multicenter, Phase II/III study of comparing $1 \mathrm{M}$ Gd-BT-DO3A with 0.5 M Gd-HT-DO3A (0.2 mmol/kg), Katakami et $\mathrm{al}^{47}$ studied the efficacy and safety of two doses of Gd-BT-DO3A (0.1 and $0.2 \mathrm{mmol} / \mathrm{kg})$ at 1.5 and $3 \mathrm{~T} \mathrm{MRI}$ in 175 patients with brain metastases. The mean number of detected lesions per patient was $6.28,6.92$, and 6.87 for GdBT-DO3A (0.1 mmol/kg), Gd-BT-DO3A (0.2 mmol/kg), and Gd-HT-DO3A, respectively. Overall clinical performance of Gd-BT-DO3A at both 0.1 and $0.2 \mathrm{mmol} / \mathrm{kg}$ was very similar to the $0.2 \mathrm{mmol} / \mathrm{kg}$ Gd-HT-DO3A. Another multicentric randomized intraindividual crossover comparison of $1 \mathrm{M}$
Gd-BT-DO3A with 0.5 M Gd-DOTA in 136 brain tumor patients at $1.0 \mathrm{~T}$ MRI was reported by Anzalone et al. ${ }^{48}$ At the dose of $0.1 \mathrm{mmol} / \mathrm{kg}$ Gd-BT-DO3A, there was a significantly higher qualitative and quantitative preference by independent blinded readers for Gd-BT-DO3A when compared to Gd-DOTA.

Voth et $\mathrm{a}^{52}$ reviewed and performed an integrated analysis of 34 clinical trials to assess the safety and tolerability of Gd-BT-DO3A. The review involved 4549 patients treated with gadobutrol for various clinical indications, including the CNS imaging $(n=2292)$. These trials were prospectively planned and conducted between the years of 1993 and 2009. A majority of the patients $(n=2434)$ received the generally recommended dose of $0.1( \pm 0.01) \mathrm{mmol} / \mathrm{kg}$ body weight. The rest of the patients received from less than 0.09 to $0.51 \mathrm{mmol} / \mathrm{kg}$ body weight. Out of the total enrolled patients, $182(4.0 \%)$ reported one or more adverse events. Out of all patients who had CNS imaging, 106 (4.6\%) also reported one or more adverse events. In comparison, 74 $(4.0 \%)$ AEs were reported in 1822 patients treated with similar GBCAs (Gd-DTPA, $n=912$; Gd-HP-DO3A, $n=555$; Gd-DTPA-BMEA, $n=227$; Gd-DTPA-BMA, $n=150$ ). The most common AEs were headache, nausea, fever, and dysgeusia. Similar incidence rates were observed in pediatric patients $(5.8 \%)$, patients with severe or moderate renal impairment $(2.5 \%)$, patients with severe or moderate hepatic impairment (4.2\%), and patients with cardiovascular disorders $(2.8 \%)$. A review of post-marketing surveillance data from more than 5.7 million estimated gadobutrol administrations showed a total of $1175(0.02 \%)$ AEs were reported. There were ten reported NSF for the entire reporting period up to February 2011. The review concluded that Gd-BTBO3A has an excellent safety profile and a positive benefit risk profile when used in clinically indicated CE-MRI.

\section{A potential advantage of using gadobutrol in CE-MRI of the brain}

Gd-BT-DO3A is a non-ionic, macrocyclic GBCA and was first approved in 1998 for clinical use in Switzerland. It is now approved for clinical use in 66 countries worldwide, including the EU, USA, Australia, Canada, China, South Africa, Mexico, New Zealand, Turkey, and some Eastern European and Asian countries. ${ }^{53}$ Gd-BT-DO3A is composed of a macrocyclic structure which has been shown to be more kinetically stable in vitro than GBCAs with linear, open-chain structures. This high stability may minimize the possibility of free toxic $\mathrm{Gd}^{+3}$ ions being released in vivo. Preclinical and clinical studies have shown that it has at least equivalent if 
not better efficacy and safety profiles to other similar GBCAs. However, Gd-BT-DO3A has a distinguishing feature that it is the only clinical agent commercially available in a formulation of 1.0 M concentration (Table 2). With this higher Gd concentration, Gd-BT-DO3A at 1.0 $\mathrm{M}$ has the highest in vitro $T_{1}$ shortening effect per unit volume compared with other GBCAs at $0.5 \mathrm{M}$. Clinically, the double concentrated Gd-BT-DO3A allows for injection volume reduction without dose level changes and the compact bolus injected is better defined in vivo. This has been proven to be advantageous for some time-resolved MRI studies such as brain perfusion MRI or contrast-enhanced MRA. ${ }^{49,50}$ It is possible that even with the blood dilution and circulation, the double concentrated agent may still localize in the CNS at a relatively higher concentration than other comparable GBCAs. As a result, Gd-BT-DO3A may be able to achieve better contrast enhancement of brain lesion than other similar GBCAs at the same dose level. In light of potential NSF events associated with the use of all GBCAs, ${ }^{20,51}$ the probability of increasing their clinical efficacy without exposing the patient to a higher dose level may make this advantage more significant. Recent published multicenter clinical trials ${ }^{45-48}$ appeared to support this potential advantage of using Gd-BT-DO3A for CE-MRI of the brain. However, there is insufficient evidence to suggest that the use of Gd-BT-DO3A will decrease the incidence of adverse events associated with the use of GBCAs.

\section{Acknowledgment/Disclosure}

The authors report no conflicts of interest in this work. Molecular Imaging and Contrast Agents Database (www. MICAD.NIH.gov) is an Intramural Research Program (National Library of Medicine) of the National Institutes of Health.

\section{References}

1. Burtea C, Laurent S, Vander Elst L, Muller RN. Contrast agents: magnetic resonance. Handb Exp Pharmacol. 2008;(185 Pt 1):135-165.

2. Strijkers GJ, Mulder WJ, van Tilborg GA, Nicolay K. MRI contrast agents: current status and future perspectives. Anticancer Agents Med Chem. 2007;7(3):291-305.

3. Giesel FL, Mehndiratta A, Essig M. High-relaxivity contrast-enhanced magnetic resonance neuroimaging: a review. Eur Radiol. 2010; 20(10):2461-2474.

4. Roberts TP, Chuang N, Roberts HC. Neuroimaging: do we really need new contrast agents for MRI? Eur J Radiol. 2000;34(3):166-178.

5. Rinck PA, Myhr G. Gadolinium chelates: clinical applications. In: Dawson P, Cosgrove DO, Grainger RG, editors. Textbook of Contrast Media. Oxford, UK: Isis Medical Media Ltd; 1999:333-353.

6. Bellin MF, Van Der Molen AJ. Extracellular gadolinium-based contrast media: an overview. Eur J Radiol. 2008;66(2):160-167.

7. Morcos SK. Extracellular gadolinium contrast agents: differences in stability. Eur J Radiol. 2008;66(2):175-179.

8. Lin SP, Brown JJ. MR contrast agents: physical and pharmacologic basics. J Magn Reson Imaging. 2007;25(5):884-899.
9. Kuo PH. Gadolinium-containing MRI contrast agents: important variations on a theme for NSF. J Am Coll Radiol. 2008;5(1): 29-35.

10. Niendorf HP, Alhassan A, Geens VR, Clauss W. Safety review of gadopentetate dimeglumine. Extended clinical experience after more than five million applications. Invest Radiol. 1994;29(Suppl 2): S179-S182.

11. Duyn JH, Koretsky AP. Novel frontiers in ultra-structural and molecular MRI of the brain. Curr Opin Neurol. 2011;24(4):386-393.

12. Gore JC, Manning HC, Quarles CC, Waddell KW, Yankeelov TE. Magnetic resonance in the era of molecular imaging of cancer. Magn Reson Imaging. 2011;29(5):587-600.

13. Bogdanov A Jr, Mazzanti ML. Molecular magnetic resonance contrast agents for the detection of cancer: past and present. Semin Oncol. 2011;38(1):42-54.

14. Gallagher FA. An introduction to functional and molecular imaging with MRI. Clin Radiol. 2010;65(7):557-566.

15. Rinck PA, Muller RN. Field strength and dose dependence of contrast enhancement by gadolinium-based MR contrast agents. Eur Radiol. 1999;9(5):998-1004.

16. Rebeles F, Fink J, Anzai Y, Maravilla KR. Blood-brain barrier imaging and therapeutic potentials. Top Magn Reson Imaging. 2006;17(2):107-116.

17. Natalin RA, Prince MR, Grossman ME, Silvers D, Landman J. Contemporary applications and limitations of magnetic resonance imaging contrast materials. J Urol. 2010;183(1):27-33.

18. Idee JM, Port M, Robic C, Medina C, Sabatou M, Corot C. Role of thermodynamic and kinetic parameters in gadolinium chelate stability. J Magn Reson Imaging. 2009;30(6):1249-1258.

19. Laurent S, Elst LV, Muller RN. Comparative study of the physicochemical properties of six clinical low molecular weight gadolinium contrast agents. Contrast Media Mol Imaging. 2006;1(3):128-137.

20. Sherry AD, Caravan P, Lenkinski RE. Primer on gadolinium chemistry. J Magn Reson Imaging. 2009;30(6):1240-1248.

21. Platzek J, Blaszkiewicz P, Gries H, et al. Synthesis and structure of a new macrocyclic polyhydroxylated gadolinium chelate used as a contrast agent for magnetic resonance imaging. Inorg Chem. 1997; 36(26):6086-6093.

22. Laurent S, Elst LV, Copoix F, Muller RN. Stability of MRI paramagnetic contrast media: a proton relaxometric protocol for transmetallation assessment. Invest Radiol. 2001;36(2):115-122.

23. Port M, Idee JM, Medina C, Robic C, Sabatou M, Corot C. Efficiency, thermodynamic and kinetic stability of marketed gadolinium chelates and their possible clinical consequences: a critical review. Biometals. 2008;21(4):469-490.

24. Perazella MA, Rodby RA. Gadolinium use in patients with kidney disease: a cause for concern. Semin Dial. 2007;20(3):179-185.

25. Grobner T, Prischl FC. Gadolinium and nephrogenic systemic fibrosis. Kidney Int. 2007;72(3):260-264.

26. Pedersen M. Safety update on the possible causal relationship between gadolinium-containing MRI agents and nephrogenic systemic fibrosis. J Magn Reson Imaging. 2007;25(5):881-883.

27. Cheng KT. Gadobutrol. Gd-DO3A-butrol. In: Molecular Imaging and Contrast Agent Database (MICAD) [database on the Internet]. Bethesda (MD): National Library of Medicine (US), NCBI; 2004-2012. Available from: http://www.ncbi.nlm.nih.gov/books/NBK23589/. Accessed February 9, 2012.

28. Gadovist ${ }^{\circledR}$ [product information]. 2010. Available from: http:// www.medsafe.govt.nz/profs/datasheet/g/Gadovistinj.pdf. Accessed February 9, 2012.

29. Vogler H, Platzek J, Schuhmann-Giampieri G, et al. Pre-clinical evaluation of gadobutrol: a new, neutral, extracellular contrast agent for magnetic resonance imaging. Eur J Radiol. 1995;21(1):1-10.

30. Pintaske J, Martirosian P, Graf H, et al. Relaxivity of gadopentetate dimeglumine (magnevist), gadobutrol (gadovist), and gadobenate dimeglumine (multihance) in human blood plasma at $0.2,1.5$, and 3 Tesla. Invest Radiol. 2006;41(3):213-221. 
31. Fink C, Bock M, Kiessling F, Delorme S. Interstitial magnetic resonance lymphography with gadobutrol in rats: evaluation of contrast kinetics. Invest Radiol. 2002;37(12):655-662.

32. Frigeni V, Miragoli L, Grotti And A, Lorusso V. Comparative study between gadobenate dimeglumine and gadobutrol in rats with brain ischemia: evaluation of somatosensory evoked potentials. Invest Radiol. 2001;36(10):561-572.

33. Kawai J, Takahashi M, Kato N, Takashima K, Miyazawa T. Comparison of a 1.0 molar and a 0.5 molar formulation of gadobutrol in dynamic MR imaging of the liver in rats with hepatocellular carcinoma. Magn Reson Imaging. 1999;17(1):91-97.

34. Le Duc G, Corde S, Charvet A, et al. In vivo measurement of gadolinium concentration in a rat glioma model by monochromatic quantitative computed tomography: comparison between gadopentetate dimeglumine and gadobutrol. Invest Radiol. 2004;39(7):385-393.

35. Reimer P, Allkemper T, Bremer C, et al. Assessment of reperfusion injury by means of MR contrast agents in rat liver. $J$ Magn Reson Imaging. 1997;7(3):490-494.

36. Attenberger UI, Runge VM, Jackson CB, et al. Comparative evaluation of lesion enhancement using $1 \mathrm{M}$ gadobutrol vs 2 conventional gadolinium chelates, all at a dose of $0.1 \mathrm{mmol} / \mathrm{kg}$, in a rat brain tumor model at 3 T. Invest Radiol. 2009;44(5):251-256.

37. Attenberger UI, Runge VM, Morelli JN, Williams J, Jackson CB, Michaely HJ. Evaluation of gadobutrol, a macrocyclic, nonionic gadolinium chelate in a brain glioma model: comparison with gadoterate meglumine and gadopentetate dimeglumine at $1.5 \mathrm{~T}$, combined with an assessment of field strength dependence, specifically 1.5 versus $3 \mathrm{~T}$. J Magn Reson Imaging. 2010;31(3):549-555.

38. Kramer H, Runge VM, Naul LG, Loynachan AT, Reiser MF, Wintersperger BJ. Brain MRI with single-dose $(0.1 \mathrm{mmol} / \mathrm{kg})$ Gadobutrol at $1.5 \mathrm{~T}$ and $3 \mathrm{~T}$ : comparison with $0.15 \mathrm{mmol} / \mathrm{kg}$ Gadoterate meglumine. AJR Am J Roentgenol. 2010;194(5):1337-1342.

39. Staks T, Schuhmann-Giampieri G, Frenzel T, Weinmann H, Lange L, Platzek J. Pharmacokinetics, dose proportionality, and tolerability of gadobutrol after single intravenous injection in healthy volunteers. Invest Radiol. 1994;29(7):709-715.

40. Essig M, Lodemann KP, Le-Huu M, Bruning R, Kirchin M, Reith W. Intraindividual comparison of gadobenate dimeglumine and gadobutrol for cerebral magnetic resonance perfusion imaging at $1.5 \mathrm{~T}$. Invest Radiol. 2006;41(3):256-263.

41. Tombach B, Heindel W. Value of 1.0-M gadolinium chelates: review of preclinical and clinical data on gadobutrol. Eur Radiol. 2002; 12(6): 1550-1556.

42. Huppertz A, Rohrer M. Gadobutrol, a highly concentrated MR-imaging contrast agent: its physicochemical characteristics and the basis for its use in contrast-enhanced MR angiography and perfusion imaging. Eur Radiol. 2004;14(Suppl 5):M12-M18.
43. Tombach B, Bremer C, Reimer P, et al. Pharmacokinetics of $1 \mathrm{M}$ gadobutrol in patients with chronic renal failure. Invest Radiol. 2000;35(1):35-40.

44. Hahn G, Sorge I, Gruhn B, et al. Pharmacokinetics and safety of gadobutrol-enhanced magnetic resonance imaging in pediatric patients. Invest Radiol. 2009;44(12):776-783.

45. Anzalone N, Gerevini S, Scotti R, Vezzulli P, Picozzi P. Detection of cerebral metastases on magnetic resonance imaging: intraindividual comparison of gadobutrol with gadopentetate dimeglumine. Acta Radiol. 2009;50(8):933-940.

46. Kim ES, Chang JH, Choi HS, Kim J, Lee SK. Diagnostic yield of double-dose gadobutrol in the detection of brain metastasis: intraindividual comparison with double-dose gadopentetate dimeglumine. AJNR Am J Neuroradiol. 2010;31(6):1055-1058.

47. Katakami N, Inaba Y, Sugata S, et al. Magnetic resonance evaluation of brain metastases from systemic malignances with two doses of gadobutrol $1.0 \mathrm{~m}$ compared with gadoteridol: a multicenter, phase ii/iii study in patients with known or suspected brain metastases. Invest Radiol. 2011;46(7):411-418.

48. Anzalone N, Scarabino T, Venturi C, et al. Cerebral neoplastic enhancing lesions: Multicenter, randomized, crossover intraindividual comparison between gadobutrol $(1.0 \mathrm{M})$ and gadoterate meglumine $(0.5 \mathrm{M})$ at $0.1 \mathrm{mmolGd} / \mathrm{kg}$ body weight in a clinical setting. Eur J Radiol. 2011. Epub Sep 2.

49. Goyen M, Herborn CU, Vogt FM, et al. Using a 1 M Gd-chelate (gadobutrol) for total-body three-dimensional MR angiography: preliminary experience. J Magn Reson Imaging. 2003;17(5):565-571.

50. Tombach B, Bremer C, Reimer P, et al. Using highly concentrated gadobutrol as an MR contrast agent in patients also requiring hemodialysis: safety and dialysability. AJR Am J Roentgenol. 2002; 178(1):105-109.

51. Ersoy H, Rybicki FJ. Biochemical safety profiles of gadolinium-based extracellular contrast agents and nephrogenic systemic fibrosis. J Magn Reson Imaging. 2007;26(5):1190-1197.

52. Voth M, Rosenberg M, Breuer J. Safety of gadobutrol, a new generation of contrast agents: experience from clinical trials and postmarketing surveillance. Invest Radiol. 2011;46(11):663-671.

53. Briefing document for gadobutrol injection NDA 201,277, Bayer HealthCare Pharmaceuticals. January 21, 2011. Available from: http://www.fda. gov/downloads/AdvisoryCommittees/CommitteesMeetingMaterials/ Drugs/PeripheralandCentralNervousSystemDrugsAdvisoryCommittee/ UCM240357.pdf. Accessed February 28, 2012.
Reports in Medical Imaging

\section{Publish your work in this journal}

Reports in Medical Imaging is an international, peer-reviewed, open access journal publishing original research, reports, reviews and commentaries on all areas of medical imaging. The manuscript management system is completely online and includes a very quick and fair peer-review system, which is all easy to use.
Dovepress

Visit http://www.dovepress.com/testimonials.php to read real quotes from published authors. 